\title{
Higher Education and Economic Development - Perspective and Prospects
}

\author{
Elizabeth Margaret, N. V. Kavitha \\ St. Ann's College for Women, Hyderabad, India
}

\begin{abstract}
India stands at a critical point on its path to be among the fastest growing economies of the world. The nation however is faced with paradoxes. India needs to leverage its vast demographic potential by educating and training over 130 million people in the age group of 18-23 years with skills and capabilities relevant to the demands of a modern knowledge based economy. Further, there remains an urgent need to reform the vast and unwieldy legacy higher education system that seems to have lost much of its relevance in today's technologically advanced and connected world. The education infrastructure in the country is inadequate to support our ambitious targets of increased enrolment, while it faces challenges of quality and relevance to the job market and cannot provide universal access to training and education.

The Twelfth Five-Year Plan (2012-17) of the statutory body responsible for governing higher education in India opens with: 'Higher education in India is passing through a phase of unprecedented expansion, marked by an explosion in the volume of students, a substantial expansion in the number of institutions and a quantum jump in the level of public funding'.

In this context the present paper makes an attempt to examine the various challenges of Higher Education in India that need to be addressed based upon the analysis of primary data obtained in survey. HEIs have a commitment to the development of a knowledge based society in its mission to move towards faster economic development.
\end{abstract}

\section{Introduction}

In today's information societies, economic growth and development are driven by Knowledge. Education enhances people's productivity, creativity and encourages entrepreneurship and technological advances. In addition it plays a very key role in securing economic and social progress and improving income distribution. Education is considered to have a strong connect with social and economic development. In contemporary times when the focus is on the 'knowledge economy' the role of education becomes all the more important in the development of human capital.
Higher education institutions are a major source for providing the human capital required for knowledge production.

As the Organization for Economic Co-operation and Development (OECD 2008) has recently pointed out, tertiary education contributes to social and economic development through four major missions:

- The formation of human capital (primarily through teaching)

- The building of knowledge bases (primarily through research and knowledge development)

- The dissemination and use of knowledge (primarily through interactions with knowledge users)

- The maintenance of knowledge (primarily through inter-generational storage and transmission of knowledge).

\section{Role of Higher Education in Economic Development}

The role of higher education as a major driver of economic development is well established, and this role will increase as further changes in technology, globalization, and demographics impact the nation. To remain competitive in light of these changes, regions will need to improve productivity and adopt an innovative spirit. HE system especially has to be reengineered to promote interactive, collaborative and active learning. Re-engineering is required as the country is facing many challenges, such as financing and management, access, equity, relevance and reorientation of policies and programs for laying emphasis on values, ethics and quality of higher education.

Higher education has the capacity, knowledge, and research necessary to help achieve these goals. Advancement of technology, cost of education, global competition and society expectations are the major factors in transformation.

\section{Demographic landscape of $\mathrm{HE}$ in India}

India has one of the largest higher education systems in the world and has witnessed an impressive growth over the years. The number of higher educational institutions (HEIs) has increased from about 30 universities and 695 colleges in 195051 to about 700 universities (as of 2012-13) and 35,000 colleges (as of 2011-12) as per a recent UGC report. With an annual enrolment of above 25 million 
(including enrolment under Open and Distance Learning system), India is today ranked as the third largest higher education system in the world after US and China.

In a move to transform the higher education sector in the country, the government has in the recent past initiated a set of reformatory measures, which are expected to address some of the challenges especially those of development of an efficient funding mechanism, improvement of quality in existing institutions and participation of top foreign universities. These initiatives will have to be further strengthened and expanded to cover much larger number of institutions to be effective. Further, an efficient monitoring mechanism for time-bound implementation as well as impact assessment of these schemes will also have to be undertaken. The institutions need to focus on knowledge generation from learners' perspective and with a view to address the needs of the society.

\section{Promoting Knowledge based Economy: The Need}

The Prime Minister, Dr. Manmohan Singh (2005) has optimistically forecasted that the 21st Century will be the " knowledge century", by which he refers to the socio - economic transformation that the country is projected to go through in the 21 st century as a result of knowledge creation. In the knowledgebased economy, the science system must balance not only its roles of knowledge production (research) and knowledge transmission (education and training) but also the third function of transferring knowledge to economic and social actors, especially enterprises, whose role is to exploit such knowledge. Higher education institutions have a critical role in supporting the development of knowledge economy since they are the basic green houses for nurturing future entrepreneurs, professionals, scientists and other specialists.

In this backdrop a pilot survey has been conducted by the authors to review the role of Higher education in Economic development on the various facets and challenges of Higher Education in India towards its economic development. And the paper focuses on accountability and performance appraisal in HEI and tries to understand the perceptions of professors and associate professors with regards to the challenges in higher education in general and also with special reference on accountability of facilitators in Higher Education Institutions ((HEIs). A structured questionnaire was framed and executed to 120 faculty members working in different HEIs in Hyderabad, Andhra Pradesh, India.

\section{Aims and Objectives}

The Aims and Objectives of the study are:

- To examine the various facets of higher education towards economic development.

- To analyze the perceptions of the sample respondents with regards to $\mathrm{HE}$ and Economic development

- To evolve a model in measuring performance appraisal of the facilitators in HEI.

\subsection{Higher Educational Institutions vs. Economic Development}

It is an established fact that Higher education institutions (HEIs) play a key role as a major change instrument of economic development. Knowledge generation in the age of information revolution requires a new kind of institutional re-engineering in governance, teaching learning process, evaluation practices that could address the learners' need much more effectively. Higher education prepares a quality workforce by offering instructional programs, matching instruction to the needs of business and industry. By mobilizing HEIs for socio-economic development through skills, entrepreneurship and innovation, they can become leaders in global knowledge economy.

Certain key aspects were identified and the respondents were called upon to rate the aspects in terms of their contribution to Economic Development. The data collected is presented in Graph 1 below:

Graph 1. HEIs vs. Economic Development

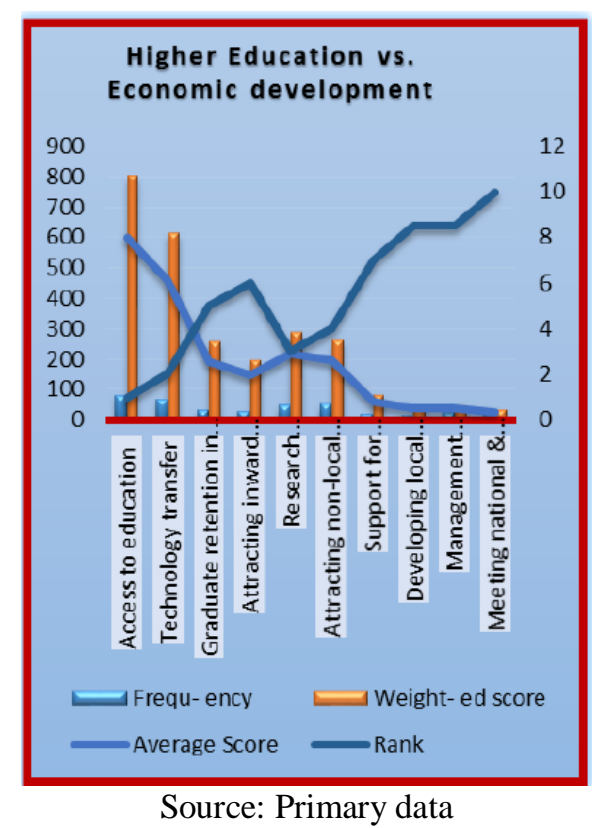


It is evident from the data that Access to education, Technology transfer, Research collaboration with industry, attracting non local students to the region and Graduate retention in local region were given top 1 to 5 ranks respectively and they are the five main key factors considered for Economic development.

\subsection{HEIs vs. Measures to be taken towards Economic Development}

While examining the present status of HEIs we find that there is a need of reengineering the education system in HEIs. HE system requires reengineering or redesigning to meet the needs of the economic units (industry, agriculture/services etc.) in a knowledge society that ensures relevance and availability. The reengineered system should provide education that fosters a spirit of enquiry and research creativity and entrepreneurship. The respondents were asked to name the five major programs to be taken up for fostering global competencies. The data is tabulated and presented in graph 2 below.

Graph 2. HEIs vs. Measures to be taken towards Economic development

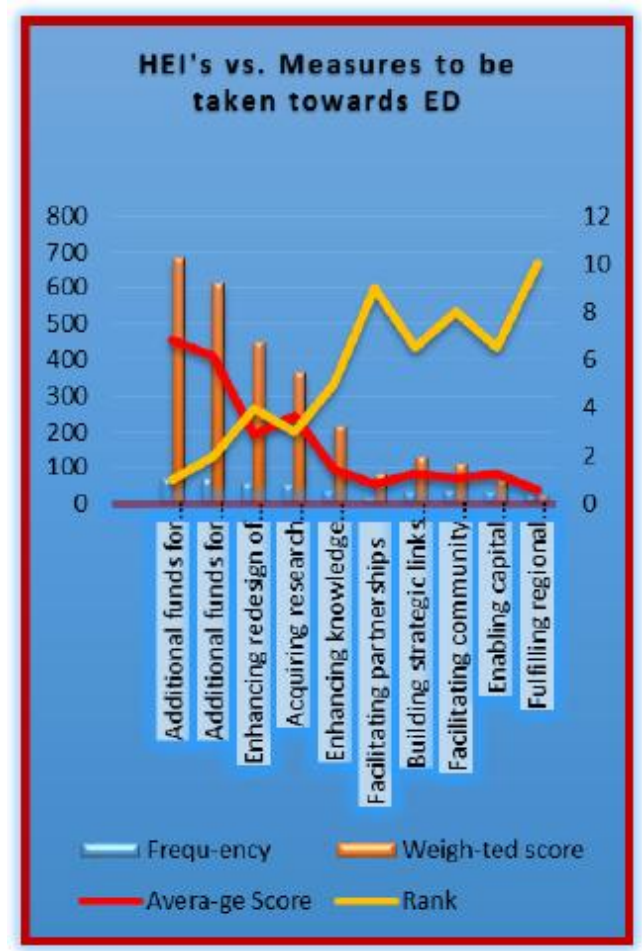

Source: Primary Data

It is clear from the table above that the respondents have rated 1st rank to Additional funds for teaching and training followed by Additional funds for research, Acquiring research equipment, enhancing redesign of curriculum and Enhancing knowledge of labour market needs.

\subsection{Indicators of enhancement in HEIs vs. Perceptions of the respondents}

Teaching excellence is the key to a strong and growing regional economy (Sampson, 2004).Curricular reforms leading to regular revision and upgrading of curricula, introduction of semester system, choice- based credit system, change in teaching pedagogy-ICT enabled teaching, training the educators, learner centric approach, examination reforms and adequate infrastructure and technology are to take place in all HEIs to build state of the art education.

The perception of the respondents was recorded in order to understand the areas in higher education that require immediate attention for enhancement. The data collected is presented in the graph 3 .

Graph 3. Indicators of enhancement in HEIs vs. Perceptions of the respondents

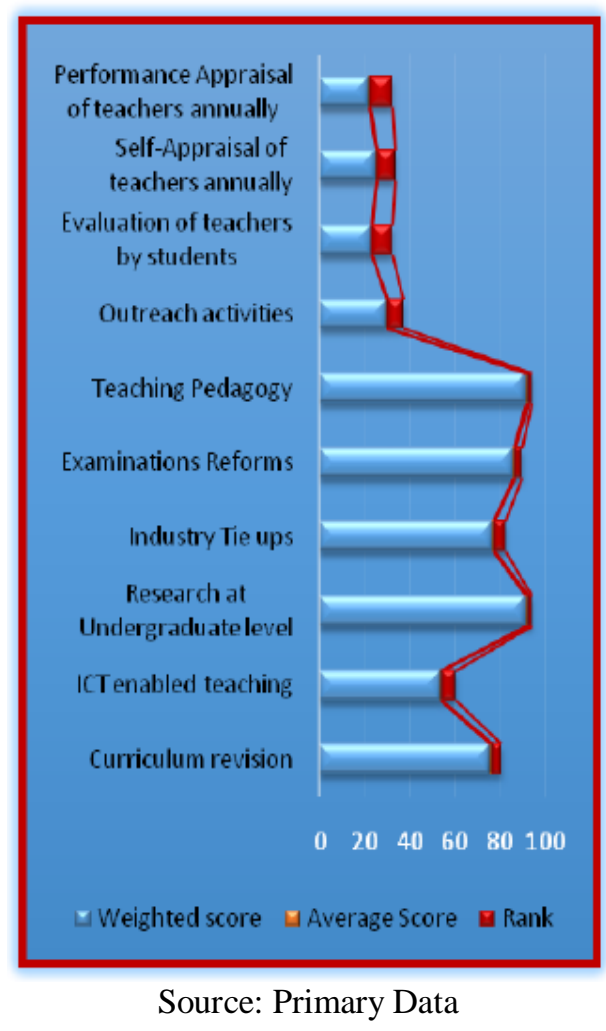

The data elicits that Teaching pedagogy and Research at undergraduate level requires top priority and immediate measures needs to be taken for its enhancement. This is followed by Examination reforms, Curriculum revision and Industry tie ups to ensure quality enhancement and sustenance in HEIs. 


\subsection{Performance appraisal of the faculty in HEIs}

Teacher performance evaluation is a good approach to bring in accountability and if implemented in the right spirit, taking care of various other aspects, performance appraisal will improve the system. The evaluation of a teacher's work should have inputs from multiple sources namely Self assessment, Assessment by students and Assessment by the academic head/s and should be based on multiple parameters like class room teaching, holding of tutorials, availability to students, participating in faculty meetings, guiding and carrying out research and participation in other academic and co-curricular activities of the department. The data collected in this regard is analyzed and presented in graph 4 .

Graph 4. Performance appraisal of the faculty in HEIs vs. Respondents perceptions

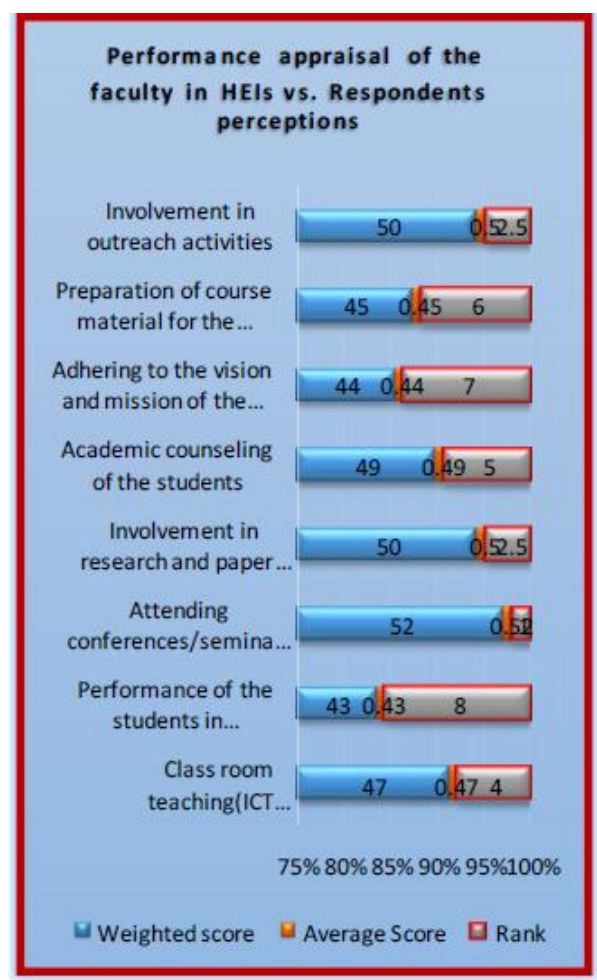

Source: Primary data

The order of priority for Performance appraisal of faculty in HEIs as stated by the respondents is as follows:

1. Attending conferences/seminars and presenting papers

2. Involvement in research and paper publications

3. Involvement in outreach activities

4. Class room teaching(ICT enabled teaching)

5. Academic counseling of the students
6. Preparation of course material for the papers taught/Writing text books

7. Adhering to the vision and mission of the institution where he/she is working

8. Performance of the students in university /summative Exams

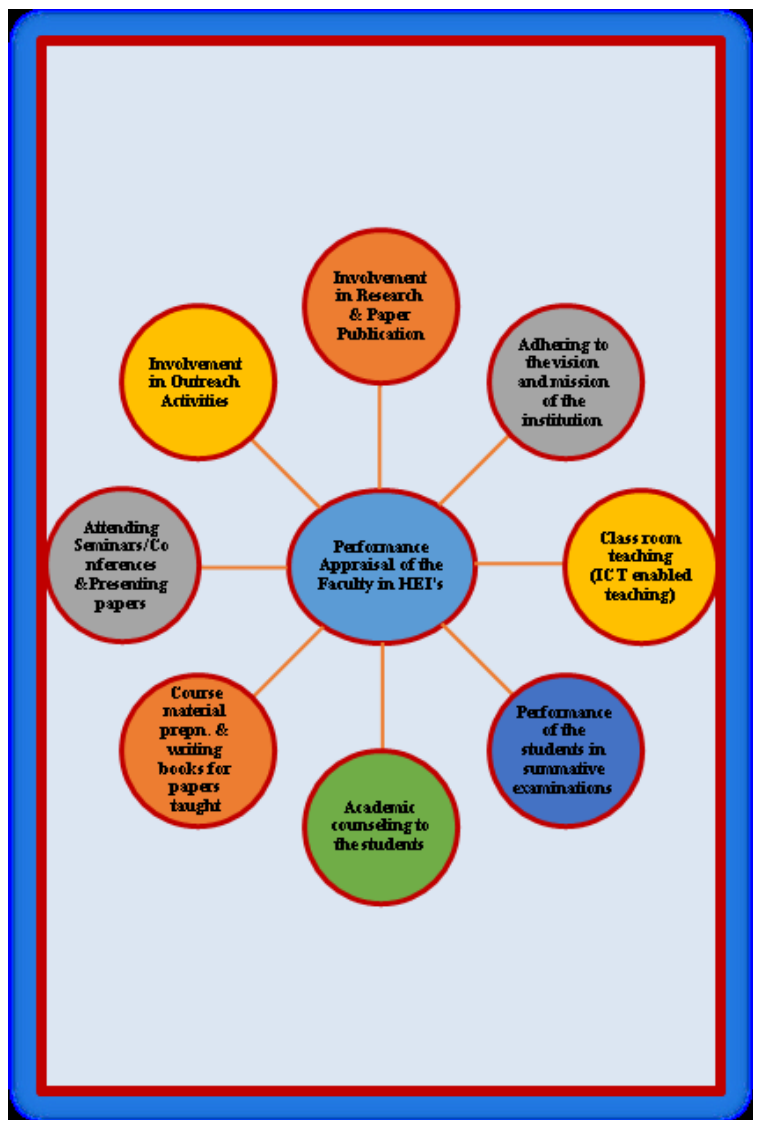

Figure 1. Indicators of Performance appraisal of faculty in HEIs

The Key findings of the survey are as follows:

- $88 \%$ of the respondents felt due importance to be given for raising educational levels to create a quality workforce.

- $76 \%$ of the sample opined that training and support to the faculty is the need of the hour.

- $68 \%$ of the faculty felt that learning and teaching process from pre-school to graduate need to be improved,

- $60 \%$ have voted for enhancing the technology infrastructure

- $56 \%$ requires disseminating research and promoting technology transfer

- $52 \%$ wants amenities for providing lifelong learning opportunities

- $44 \%$ expressed the need for strong and visible roles in regional initiatives - Identifying the needs of business and industry 
- $96 \%$ of the respondents were in favor of Accountability in teaching Profession and only $4 \%$ were against the idea.

- $100 \%$ of the respondents opined that student's performance is the only factor in accessing teacher's accountability. Whereas $24 \%$ of the respondents felt that research contribution can be the ideal factor in accessing teacher's accountability.

\section{Suggested Reforms in HEIs leading to Knowledge management thus paving way to Faster Economic Development}

HEIs have a number of roles to fulfill and finding the right balance between the following qualities is a challenge for all HEIs.

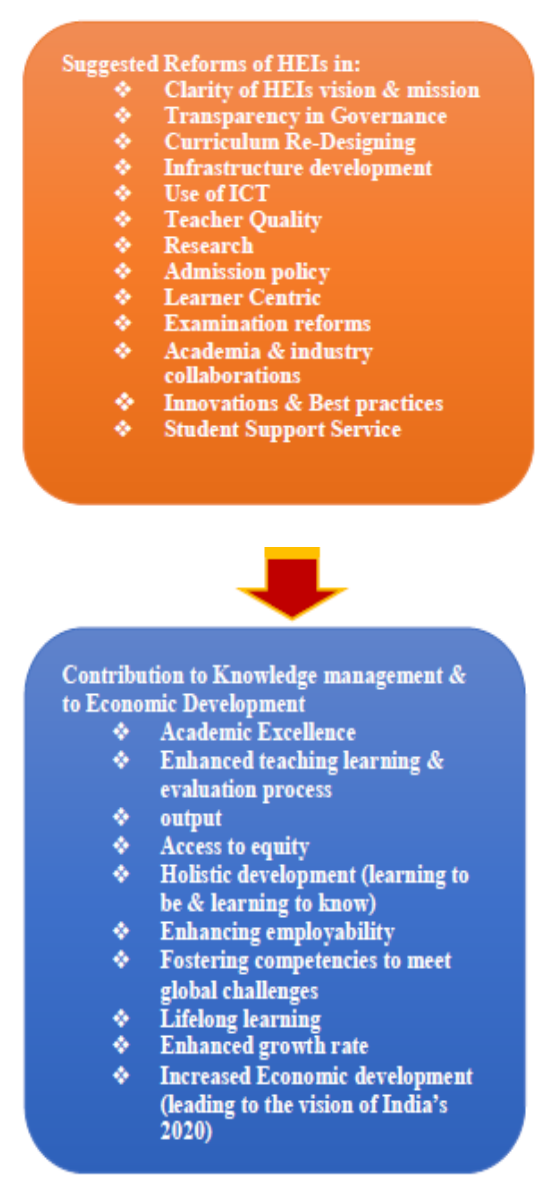

Figure 2. Suggested reforms

\section{Conclusions}

Higher education has been increasingly recognized as playing a central role in human, social and economic development. In contemporary "knowledge societies" and in the face of pressures and changes related to globalization, the role is progressively more important.
It is felt that the successful implementation of reforms in HEIs requires five major factors, namely (a) Commitment for achieving excellence in all fields (b) Research and development so as to facilitate innovation and leverage the growing opportunities (c) Academic and financial autonomy for emphasis on interdisciplinary programs (d) Industry - Institute Partnership and (e) International collaboration. It is evident from the study that HEIs have an institutional commitment to development of a knowledge based society as part of its mission to move towards faster economic development.

\section{References}

[1] Altbach, P. (2005) "Higher Education in India" in The Hindu, 12-04-2005 available online at www.thehindu.com

[2] Altbach P. and Levy D. (eds.) (2005) Private Higher Education: A Global Revolution Rotterdam: Sense Pub.

[3] Agarwal, Pawan. (2009). Indian Higher Education Envisioning the future, Sage Publications (P) Ltd., New Delhi

[4] Braddock, R. and Neave G. (2002) "Research Management in Higher Education"Higher Education Policy 15. pp. 313-330.

[5] Farenga, Stephen J. (Ed) (2005) Encyclopaedia of Education and Human Development. M.E. Sharpe.

[6] Galbraith, M. (Ed.). (2004) Adult learning methods: A guide for effective instruction 3rd. ed. Malabar, FL: Krieger.

[7] MHRD (2013). Annual Status of Higher Education of States and UTs in India, 2013.

[8] OECD: Education at a glance 2008: http://www.oecd.org/education/skills-beyondschool/41284038.pdf

[9] Sampson, D. June 10, 2004. Remarks for the National Coalition for Advanced Manufacturing, Washington, D.C.

[10] UNESCO/Ketele J.M. (2003) "Higher Education in the 21st Century" UNESCO Policy Paper 11 UGC (2013). Higher Education in India, UGC, New Delhi. 